\title{
Spontaneous Vesicle Formation in Aqueous Mixtures of Cationic Gemini Surfactant and Sodium Lauryl Ether Sulfate
}

\author{
Ho-Young Cheon, Noh-Hee Jeong," and Hong-Un Kim ${ }^{\dagger}$ \\ Deparment of Industrial and Engineering Chemistry. Chungbuk National Lniversity, Cheongit 360-763, Korea \\ "E-mail: nhjeongachungbuk.ac.kr \\ ${ }^{\dagger}$ Department of Applied Chemistry, Donglang Technical College, Seoul 152-714, Korea \\ Received January 22, 2004
}

\begin{abstract}
Molecular aggregates of surfactant molecules consisting of one or more bilayers arranged in a hollow, closed. usually spherical geometry are termed "vesicles" or "liposomes". In recent years it has been found that in certain systems the vesicular structure forms spontaneously and is long lived. and it has been suggested that these stnictures may in fact constitute the equilibrium state in these cases (as is true of micelles) This paper deals with the mixed CMC. vesicles, phase behavior. phase transition, geometrical structure. their formation and characterization in the aqueous solutions of mixed cationic/anionic surfactants șstems. TEM micrographs revealed that the vesicles were of spherical shape and that their size was of around $180 \mathrm{~nm}$. The zeta potentials are positive at CGSI-rich regions and negative at SLES-rich regions. In the region where SLES/CGSI (6/4). the zeta potentials are very small. implying that the vesicles at this surfactant ratio may be less stable. At other surfactant ratios. the vesicles are thought to be stable. supported by large absolute values of zeta potentials and little change in UV absorbance for several months.
\end{abstract}

Key Words : Vesicles. Liposomes, TEM micrographs, Zeta potentials, UV absorbance

\section{Introduction}

Vesicles are primary examples of compartmentalized liquids generated by the self-assembly of amphiphilic molecules in solution. If the surfactants are phospholipids. the vesicles in this case are called liposomes. They were first studied around 1965 as models of biological membranes. ${ }^{1-4}$ By 1970, their structure and physical-chemical characteristics had led researchers in a number of fields to investigate the potential of liposomes as carriers of therapeutical active ingredients.

Vesicles whose envelopes are made up of nonionic surfactants are called niosomes. They may have some advantages over liposomes with respect to chemical stability lower costs of the chemicals and the large amount of surfactant classes available for the design of theses vesicular structures on demand. These vesicles have been applied for cosmetic purposes very successfully. ${ }^{5}$

Vesicles are substantially valuable in biomimicking. drug delivering. ${ }^{6-4}$ sy'nthesis of nanoparticles. ${ }^{10}$ microreactors. and substrates for a variety of enzymes and proteins.

The so-called catanionic ${ }^{j-15}$ vesicles are made from mixtures of cationic and anionic surfactants. They are attracting much interest because they form spontaneously and they can be obtained from a variety of surfactants. In 1989. for the first time. Kaler et al. ${ }^{16}$ reveled the vesicle formation from mixed cationic and anionic surfactants using cetyltrimethylammonium tosylate (CTAT)/sodium dodecylbenzene sulfonate (SDBS) ${ }^{17-20}$ with single alkyl chains. Since then. catanionic vesicles have been examined in the mixtures of dodecyltrimethyl-ammonium bromide (DTAB) ${ }^{-1}$ and sodium dodecyl sulfate (SDS). 2: didodecỵldimethylammonium bromide
(DDAB) with double alkyl chain and $\mathrm{SDS}^{-3 \pi}$ with single alkyl chain. etc.

The formation of vesicles from phospholipid ${ }^{24}$ usually requires input of some form of energy. for example. ultrasonic. ${ }^{25}$ The vesicles thus formed are believed to be metastable and easy to fuse. On the other hand vesicles formed in cationic/anionic surfactant mixtures are believed to be thermodynamically stable. and their size. charge. or permeability can be readily adjusted by varying the relative amounts and/or chain lengths of the two surfactants.

The cationic gemini surfactant studied is CGS1 (Dimeric 1.2-bis(dodecyldimethyl ammonium) ethane dibromide) ${ }^{26.27}$ In these ampliphiles. two surfactant molecules are linked at the level of the head groups by an alkyl chain (spacer). containing s carbon atoms. The current interest in a gemini surfactant arises from two essential properties.

Above all. geminis tent to have much lower CMC. can produce lower surface tensions for an equivalent molar or mass concentration. and have better wetting properties than the corresponding conventional (monomeric) surfactants. In the next place. aqueous solutions of dimeric surfactants with short spacers can have very high viscosities at relatively low concentrations whereas solutions of the corresponding monomeric surfactants have low viscosities.

They are widely used as an effective emulsifier corrosion inhibitors. dispersants. anti-foaming agents. detergents. etc. Recently these compounds found also application in the solubilization of dyes and pigments in the textile industry. ${ }^{28}$ the synthesis of highly mesoporous materials. ${ }^{29}$ gene therapy. ${ }^{310}$ etc.

As for anionics. SLES (sodium lauryl ether sulfate) was used. This surfactant does not wash out the lipid of the skin 


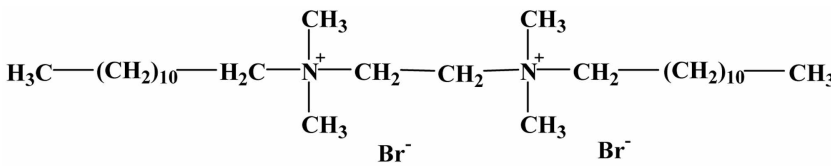

$$
\begin{aligned}
& \text { CGS1 } \\
& \mathrm{CH}_{3}-\left(\mathrm{CH}_{2}\right)_{11}-\left(\mathrm{OCH}_{2} \mathrm{CH}_{2}\right)_{3}-\mathrm{OSO}_{3}^{-} \mathrm{Na}^{+} \\
& \text {SLES }
\end{aligned}
$$

Figure 1. The chemical structures of CGS1 and SLES.

surface completely, and then keeps the skin smooth after washing. It is also highly biodegraded in water and less skinirritative than alkaline soap. SLES is widely used in cosmetics such as cleansing, cream, soap, shampoo, linse, etc. The molecular structures of surfactants are shown in Figure 1.

The CGSI/SLES surfactant mixture is composed of a Gemini surfactant and a conventional surfactant, the dianeter sinaller than any other vesicle systems. The particle size distributions is $40 \mathrm{~nm}-1.1 \mu \mathrm{m}$ and the average size is 180. Meanwhile, particle sizes of other catanionic surfactant mixtures are far bigger than the particle size of CGSI/SLES surfactant mixture. The $\mathrm{ClAB} / g$ lucuronate glycosides system (diameters up to $25 \mu \mathrm{m})^{31}$ and a DDAB/SDS surfactant system (diameters up to $40, \mu \mathrm{mm}$ ), giant vesicles was observed for instance with a differential interference optical microscope. The study on catanionic vesicles has been conducted on the mixed cationic and anionic surfactant systems with single hydrophilic head groups and single alkyl chains, or the mixed systems are composed of a cationic surfactant with one hydrophilic head group and two alkyl chains and an anionic surfactant with one hydrophilic head group and one alkyl chain. However, the study on vesicle systems of a gemini surfactant with two hydrophilic head groups and two alkyl chains and a conventional surfactant with one hydrophilic head group and single alkyl chain has very little. Hence, CGSI and SLES were selected in the present work because of these peculiar characteristics.

In this work, the properties of catanionic spontaneous vesicles $^{32-4.3}$ formed in CGS1/SLES surfactant systems, i.e. mixed $\mathrm{CMC}^{\text {,4 }}$ phase behavior and phase transition temperature of mixtures are investigated. In addition, size and structure of vesicles formed spontaneously in this mixture, mechanism of vesicle formation by geometric structural analysis, and the stability of vesicles are observed.

\section{Experimental Section}

Materials. The cationic Gemini surfactant of the type $\mathrm{N}$ a)kanediyl 1,2-ethane bis(dimethyl ammonium bromide) were prepared by the action of 1,3-dibromopropane (Aldrich Chemical Co.) on $N N$-dimethyltetradecylamine under reflux in absolute ethanol. After evaporation of solvent, the crude product was recrystallised in a mixtures of solvent (ethylacetate and acetone). The anionic surfactant SLES (Sunjin Chemical Co.) was used after recrystallization (3 times) from ethanol.

Differential Scanning Calorimeter (DSC) Measurements. Phase transition temperature was determined by using a differential scanning calorimeter (DSC 2010, TA Instruments Inc.. USA). DSC equipped with an Auto Scanning Zero was used for investigating the thermal changes of the vesicle systems. The measurement was carried out under nitrogen gas merge and the scanning range used in these experiments was from $20^{\circ} \mathrm{C}$ to $200^{\circ} \mathrm{C}$, with a scanning rate of $1{ }^{\circ} \mathrm{C}$ per minute. For each experiment 8-9 ing of sample was used.

Particle Size Measurements. The dianeter of vesicles was determined by DLS, which was made with a spectrometer of standard design (Malvern Model Mastersize $2000)$ and a He-Ne laser.

Vesicle Image Observations. Observation of vesicle formation in mixed systems at different SLES mole fractions is confirmed with an electron microscope (JEM-100CX II) using the negative-staining method for sample preparation. As soon as the surfactant mixture solution and an aqueous solution of $2 \%$ uranyl acetate (UA, $\mathrm{pH} 4$ ) were mixed volumetrically at the ratio of $2: 1$, the resultant solution was then added dropwise to a 150-Inesh copper grid coated with colloidin, sprayed with a carbon film. Extra droplet was instantly removed by using a filter paper, and then the grid was dried in a vacuum desiccator for $5 \mathrm{~h}$ as a T'EM sample.

UV-Vis Measurements. The UV-Vis spectra were recorded on a Shimadzu UV 3100 spectrophotometer at 25 " $\mathrm{C}$. The vesicles were dissolved in the water, their concentration being in the $7 \times 10^{-1} \mathrm{M}$ range.

$\zeta$-Potential Measurements. Colloidal particles accumulate charge at their surface that can be expressed as a surface potential. Surface potential is an important factor for determining the magnitude of charged-based colloidal interactions of a particle, most crucially electrostatic repulsion of other like charged particles.

Measuring the colloidal charge typically involves applying an electrical voltage to the particle and measuring the speed of movement induced. In practice, one or more layers of hydrated ions move with the particle and thus the potential determined is not that at the surface but rather at a short, undefined distance into the diffuse layer-the $\zeta$ potential.

The $\zeta$-potentials of the mixed micelles were obtained by measuring their electrophoretic mobilities with a ZetaSizer 2000 (Malvern Instruments Ltd. $)^{45}$ and by applying a Smoluchowski equation, ${ }^{46}$ in which the viscosity and dielectric constant of water of the measured temperature were used. The external DC voltage applied for the mobility measurements was constant at $100 \mathrm{~V}$. Each sample was injected to the cell by the syringe, so as to avoid the generation of bubbles in the cell. The stationary levels in the $\zeta$-potential cell were found from a van Gils plot. ${ }^{47}$

The $\zeta$-potential measurements were performed at room temperature at the upper stationary level. The arithmetic mean was taken from several $\zeta$-potential measurements of the same sample after the highest and lowest values were 
deleted. The averaged $\zeta$-potential was corrected for the retardation of the electrical double layer by Henrys function. ${ }^{.8 .1 \%}$ The $\mathrm{pHs}$ of the solutions were measured with a Hanna $\mathrm{pH}$ ineter.

\section{Results and Discussion}

Critical Micelle Concentration of CGS1/SLES/Water Systems. Figure 2 show the surface tension curve of Sl.FS CGS1 mixed surfactant systems as a function of the logarithm of the total surfactant concentration. The surface tensions decreased with increasing total surfactant concentration, and each surface tension curve had a break point. which was taken as the critical micelle concentration (CMC) of mixed surfactants. The CMCs of mixed surfactant

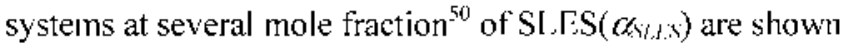
in table 1 .

General Phase Behavior of CGS1/SLES/Water Systems. The general phase behavior of CGSI/SLES/Water systems studied is presented in Figure 3 . The isotropic phase is of relatively low viscosity and is transparent. The isotropic solutions (I) appear at low surfactant concentration less than

Table I. Mixed CMC for SI.ESCGGS surfactant mistures with mixture composition at 25 and $35^{\circ} \mathrm{C}$

\begin{tabular}{|c|c|c|}
\hline SLES & $\begin{array}{c}\mathrm{CMC} \mathrm{CMC}\left(\times 10^{-1} \mathrm{~mol} / \mathrm{kg}\right) \\
\text { at } 25^{\circ} \mathrm{C}\end{array}$ & $\begin{array}{c}\mathrm{CMC}\left(\times 10^{-4} \mathrm{~mol} / \mathrm{kg}\right) \\
\text { at } 35^{\circ} \mathrm{C}\end{array}$ \\
\hline 0.0 & 5.02 & 4.17 \\
\hline 0.2 & 7.85 & 3.73 \\
\hline 0.4 & 4.14 & 0.74 \\
\hline 0.6 & 0.54 & 0.25 \\
\hline 0.8 & 1.04 & 0.68 \\
\hline 1.0 & 5.64 & 1.56 \\
\hline
\end{tabular}

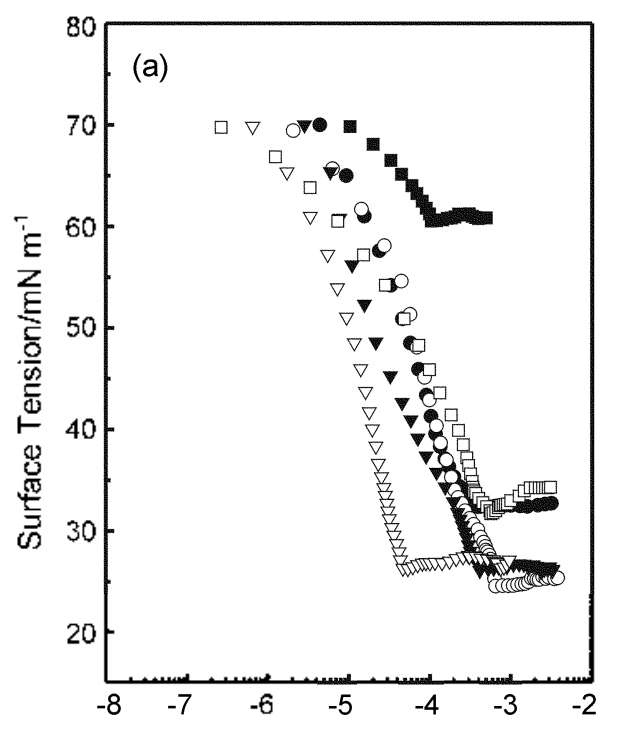

$\log$ (Surfactant Concentration, mol $/ \mathrm{kg}$ )
0.0249 (a), 0.0069 (b) wt \% for a CGSl-rich system and less than 0.0183 (a), 0.0152 (b) $w t^{\%} \%$ for a SLES-rich system (Figures 3-(a) and 3-(c) : $25{ }^{\circ} \mathrm{C}$. Figures 3-(b) and 3-(d) : 35 ${ }^{\prime \prime C}$ ). The isotropic solution channel on the CGSI-rich side is broader than that on the SLES-rich side and decrease with increasing temperature.

For $0<\alpha_{\text {s. }}<0.2$ and $0.8<\alpha_{x}, x<1,0$, the large micellar region $(\mathrm{M})$ are formed. Meanwhile, for $0.2<\alpha_{\mathrm{s} / \mathrm{s}}<0.8$. micellar fluid channel is closely connected with the vesicular channel (Figures 3-(c) and 3-(d)).

The vesicle solution channel was turbid and the turbidity increased with increasing total surfactant concentration. At the fixed total surfactant concentration the turbidity increased with increasing $\alpha_{\mathrm{y}, \mathrm{s}}$.

Phase Transition Temperature of Mixed Micelles. Phase transition from a gel state to a liquid crystalline state occurs in normal vesicular systems. A Phase transition between a gel state and a liquid crystalline state occurs because of a transition from a state of conformational order to a state of disorder. In a bilayer of vesicle membrane, too, a phase transition is occurred. This is accompanying by a sudden change as membrane fluidity, membrane permeability of small molecules and ions and miscibility between every variety of lipid.

A Phase transition is confirmed by turbidity and a dispersion intensity of light of a vesicle. When a membrane of vesicle is changed from a gel state to a liquid crystalline state, turbidity is decreased due to difference of a density of a two states and molecular packing.

A lamellar liquid crystalline phase is not formed in a 0.8 mole fraction of SLES, in which the phase transition from a solid state to an isotropic solution occurs at $25^{\circ} \mathrm{C}$. Phase transition temperature increases in a 0.2-0.6 mole fraction of SLES and then decreased suddenly. Phase transition

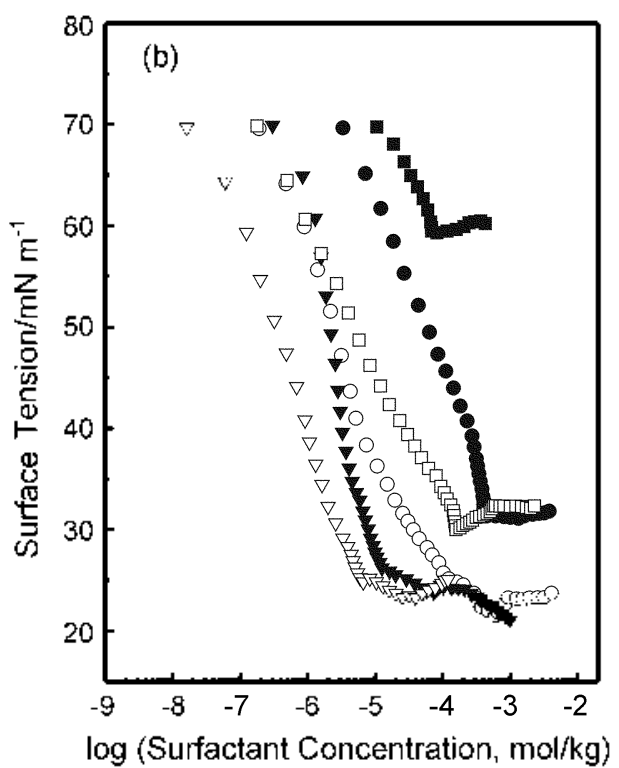

Figure 2. The plot of the surface tension vs. total surfactant concentration for SLFS.CGGS1 at $25^{\circ} \mathrm{C}$ (a) and $35^{\circ} \mathrm{C}$ (b). Molar fraction of SI.IS: $\mathbf{O}, 0: 0,0.2: \boldsymbol{\nabla}, 0.4, \forall, 0.6: \mathbf{\square}, 0.8 ;=, 1.0$ 
(a)

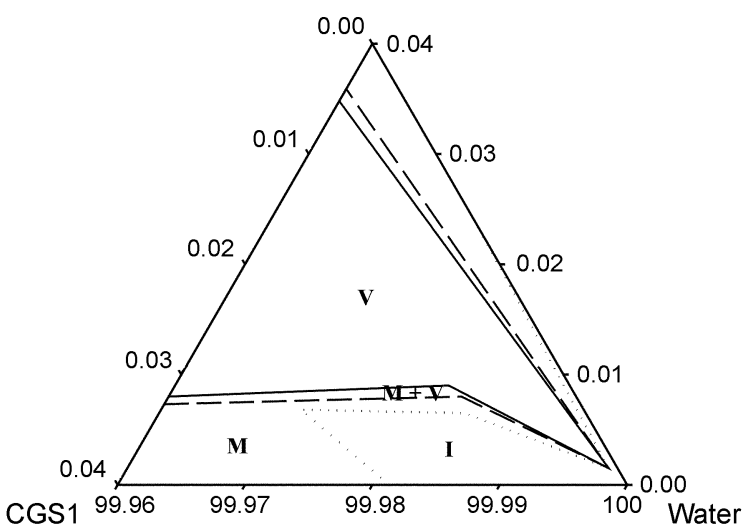

(c)

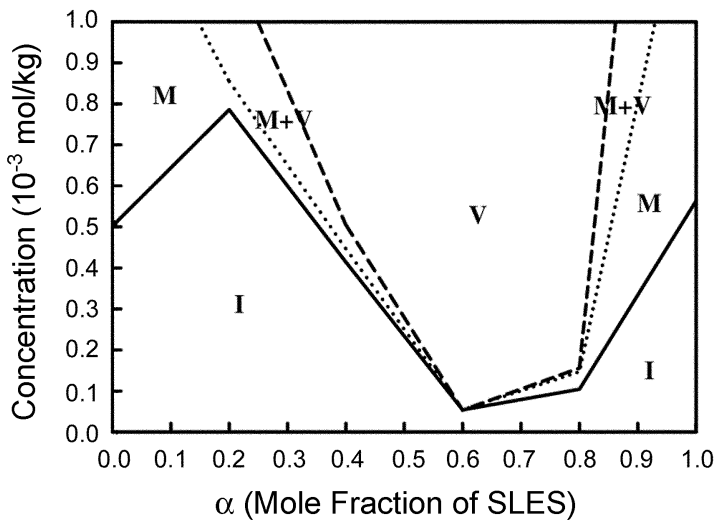

(b)

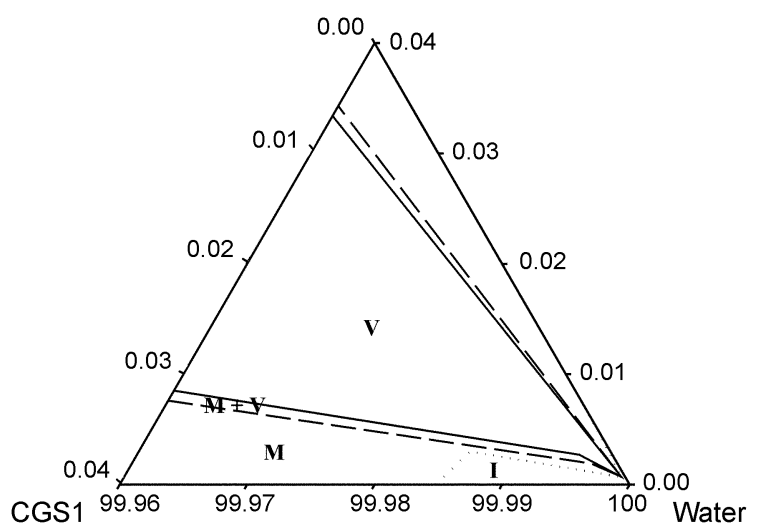

(d)

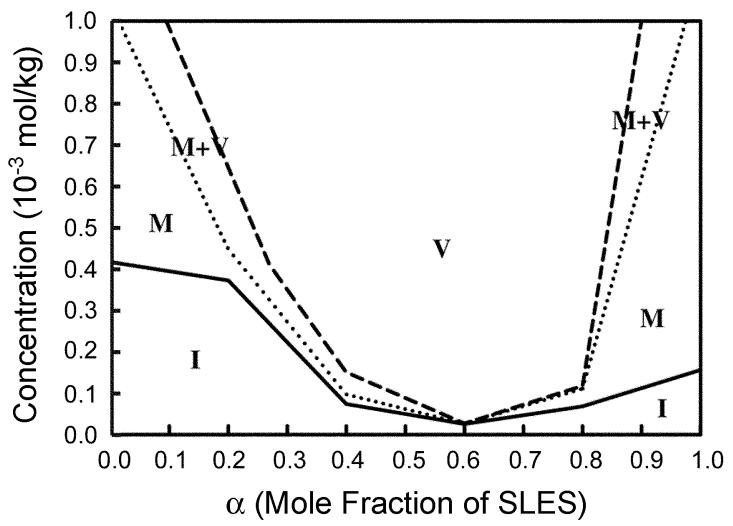

Figure 3. The phase diagram of CGS1/SLLS/Water systems at $25^{\circ}{ }^{\circ}\left((a)\right.$, (c)) and $35^{\circ} \mathrm{C}(\mathrm{b})$, (d)) in triangular coordinates ((a), (b)) and rectangular coordinates (ic). (d)). The channel of isotropic molecular solution: I. micellar solution: M. mixture of micelles and vesicles: $\mathrm{M}+$ V. vesicles: $V$.

temperature is highest at $\alpha_{\mathrm{s}, \mathrm{s}}=0.6$ because it is accompany by transition process from a very turbid precipitate to a vesicle. If it is connected with the æ-potential, the absolute value of $\zeta$-potential very small at $\alpha_{\mathrm{w}, \mathrm{x}}=0.6$. Therefore, Repulsion between the vesicles is decreased, the mixture is formed easily Multilamellar vesicle (MLV) and transition temperature from phase of inultilamellar vesicle to phase of unilamellar vesicle (ULV) become higher. Meanwhile, At $\alpha_{\mathrm{s}, \mathrm{s}: \mathrm{s}}=0.2,0.4,0.8$, the absolute value of $\zeta$-potential is considerably large. Therefore, Repulsion between the vesicles is increased and phase transition is apt to occur than $\alpha_{\mathrm{y} \text { r: }}=$ 0.6 . This phase transition was observed using DSC, and some typical DSC traces are as shown in Figure 4.

There is only one endothermic peak in Figures 4-(a), 4-(b) and 4-(d). whereas two peaks are observed in rigure 4-(c). The peak in Figure 4-(d) corresponds to the phase transition between the liquid crystalline state and the isotropic phase, and the peak in Figure 4-(a) corresponds to the phase transition between the gel state and the isotropic phase. Meanwhile, first and second peaks in Figure 4-(c) correspond to the phase transitions between the gel state and the liquid crystalline state, and the liquid crystalline state and the isotropic state, respectively. The peak in rigure 4 -(b) is the same as the first peak in Figure 4-(c). The phase transition

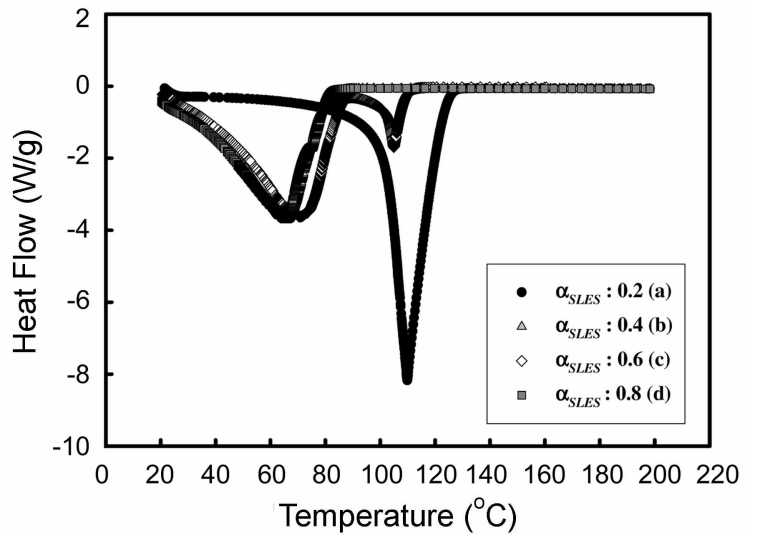

Figure 4. The DSC thennograms of 0.01 mol SLES/CCSI surfactant mixtures.

temperature in mole fraction of SLES for SLES/CGSI surfactant mixture is shown in lable 2.

Minimum Area $A_{\text {min }}$ per Surfactant and Critical Packing Parameter $\left(N_{p_{c}}\right), \Gamma_{\max }$ denotes the maximum surface excess which is a measures of how much of the interface has been changed by the surfactant depends on the structural groupings in the surfactant molecule and its orientation at the interfaces and is expressed as ${ }^{51}$ : 
Table 2, Phase transition lemperature of various $\alpha_{\text {N.t. }}$ al $0.01 \mathrm{M}$ concentration

\begin{tabular}{|c|c|c|}
\hline$\alpha_{\mathrm{Y} S \mathrm{X}}$ & $1 \mathrm{~s} T_{t y z t s,}\left({ }^{\circ} \mathrm{C}\right)$ & $2 \mathrm{nd} T_{\text {Irxm }}\left({ }^{\circ} \mathrm{C}\right)$ \\
\hline 0.2 & - & $\begin{array}{c}109.89 \\
\text { (tirled blue } \rightarrow \text { clear micelle) }\end{array}$ \\
\hline 0.4 & $\begin{array}{c}65.86 \\
\text { (turbid } \rightarrow \text { tinted bluc) }\end{array}$ & 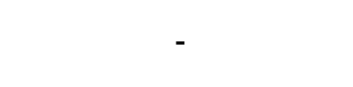 \\
\hline 0.6 & $\begin{array}{c}70.62 \\
\text { (turbid. thick blue } \rightarrow \text { tinted bluc) }\end{array}$ & $\begin{array}{c}104.97 \\
\text { (tinted bluc } \rightarrow \text { clcar micellc) }\end{array}$ \\
\hline 0.8 & $\begin{array}{c}65.88 \\
\text { (turbid. thick bluc } \rightarrow \text { tinted blue) }\end{array}$ & - \\
\hline
\end{tabular}

$$
\Gamma_{n \text { it. }}=-\frac{\left(\frac{d y}{d \log C}\right)}{2.303 n R T}
$$

Where $d \gamma / d \log C$ is the slope of $\gamma$ versus log $C$ plots at a constant absolute temperature $T$ and $R=8.314 \mathrm{~J} /$ molK. $n$ is a constant number which depends on the number of species constituting the surfactant and which are adsorbed at the interface. For gemini surfactant under study, $n$ was taken as 2 and $\Gamma_{\max }$ is measured in $\mathrm{mol} / \mathrm{m}^{2}$.

The effectiveness of adsorption is related to the interfacial area occupied by the surfactant molecules $(A)$ : the sinaller the effective cross-sectional area of the surfactant at interface, the greater is its effectiveness of adsorption.

The $\Gamma_{\max }$ values were used to calculate the minimum area ( $A_{\text {mirn }}$ in $\AA^{2}$ molecule ${ }^{-1}$ ) at the aqueous-air interface using the relationship:

$$
A_{m m}=\frac{10^{16}}{N T_{m i s,}}
$$

Where $N$ is Avogadro's number, and $A$ is in $\AA^{2}$.

According to Israelachvili et al. ${ }^{5 ? 5}$, the shape of association structures of aggregates formed from amphiphilic molecules in aqueous media is determined by the critical packing parameter $(N$, c) derived from simple geometrical considerations. The spherical micelles are formed at $0<N_{p}$, $<1 / 3$ and the cylindrical micelles are formed at $1 / 3<N_{p}<$ 1/2. For $1 / 2<N_{1}<<1$, vesicles are formed and for $N_{/}, N_{\mu}>1$, reverse micelles are formed.

$N_{\prime \prime}, V$ and $l$ values are calculated as:

$$
\begin{gathered}
N_{p_{c}}=\frac{V}{a_{0} l} \\
V=\left(27.4+26.9 N_{i}\right) 10^{-3} \mathrm{~nm}^{3} \\
l=\left(0.154-0.1265 N_{i}\right) 0.77 \mathrm{~nm}
\end{gathered}
$$

Where $V$ is the volume of hydrocarbon chain (s), $a_{t}$ is the minimum area per surfactant. $l$ is the critical chain length which corresponds to the maximum effective length that the chain can assume, and $N_{i}$ is the carbon number of alkyl group.

the values of $\Gamma_{\text {max. }}-d \gamma d \log C, A_{\text {min }}$ and $N_{j k}$ are listed in Table 3 .

At $\alpha_{\mathrm{S}, \mathrm{S}}=0.4$ and $\alpha_{\mathrm{y}, \mathrm{s}}=0.6$, the values of critical packing parameter are 0.575 and 0.641 , respectively. Hence,
Table 3. Interfacial parameters and critical packing parameter for SLLS/CGSI surlaclant mixtures with mixture composition at $25^{\circ} \mathrm{C}$.

\begin{tabular}{ccccc}
\hline$\alpha_{\text {W.SS }}$ & $10^{1.4} \Gamma_{\text {max }}$ & $-d \gamma i d \log C$ & $A_{\text {tomu }}$ & $X_{f_{\mathrm{s}}}$ \\
\hline 0.0 & 1.78 & 20.324 & 93.32 & 0.292 \\
0.2 & 2.96 & 16.884 & 56.17 & 0.484 \\
0.4 & 3.51 & 20.055 & 47.29 & 0.575 \\
0.6 & 3.91 & 22.343 & 42.44 & 0.641 \\
0.8 & 0.12 & 0.704 & 73.30 & 0.371 \\
1.0 & 1.78 & 10.170 & 93.25 & 0.292 \\
\hline
\end{tabular}

these values of $N_{/ c}$ indicate formation of vesicles. Meanwhile. for $\alpha_{Y, S}=0.2$ and $\alpha_{Y, S: S}=0.8$, these values of $N_{\text {, c }}$ imply formation of spherical micelles.

Mechanism of the Formation of Vesicles. The molecule of 1,2-ethane bis-(dimethyl dodecyl ammonium bromide) has two heads and two tails, and looks like a cylinder. We designate them by $m-s-m$, with $m$ denoting the length of the hydrocarbon chain, and s the length of the spacer connecting the two chains. SLES molecule has a linear alkyl chain, which make itself look like a conic. The combination of them forms a cuplike structure as shown in Figure 5. This result is agree with the model of Masaniko, ${ }^{5-1}$ that the conic structure is liable to form micelles and that of cylinder is liable to form bilayers, the cup-like structure forms vesicles.

After the mixing of SLES and CGSI, they form mixed micelle due to the electrostatic attraction and lay a foundation of a cuplike structure. Anionic-cationic surfactant mixtures have a much higher surface activity than their individual components due to the strong interaction between the two oppositely charged surface-active ions. With the increase of interaction, the two polar head groups of the twosurfactant molecules approach nearly. The area of the upper bottom of the cuplike structure becomes smaller. more and more molecules enter the bilayer of the vesicle, which leads to the decrease of the curvature and the increase of the diameter: But on the other hand, the more the bilayer is compressed, the closer the molecules are and the harder the outer molecules enter the inner layer of the vesicle. Therefore, the diameter of the vesicle doesnt increase any more after certain time but decrease due to the contraction of the inner layer.

From the side of the surface charge, for Figure 6-(a) $(\alpha+s)$

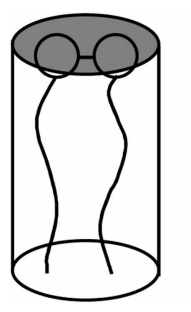

Cylinder Structure (CGS1)

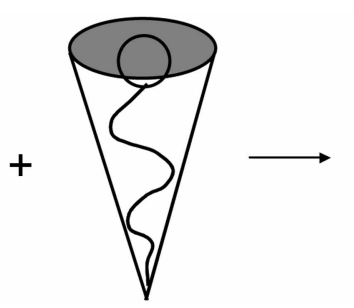

Conic Structure (SLES)

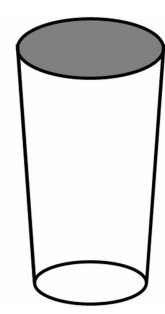

Cup-like Strueture (Vesicle)
Figure 5. The geometric structure of COS1/SLES mixed apueous solution. 
$<0.5$ ), the charge shows the negative charge. Meanwhile, for Figure $6-(b)\left(\alpha_{v},>0.5\right)$, the charge shows the positive charge. On account of the difference in the mole fraction, all of the jon pairs are unlike one another. Hence, with the exception of the ion pairs, the rest of the surfactants are located between the two ion pairs in the upper part of the bilayer. As repulsion of the two head groups increases in two surfactant molecules, the upper part of bilayer line curved like a bow, a opposite ion out of the lower part of bilayer in order to keep a state of equilibrium and they form vesicle.

Explaining in detail, because these vesicle systems are composed of a gemini surfactant and a conventional surfactant, a diameter sinaller than any other vesicle systems. For example, for Figure 6 -(a) $(\alpha s s<0.5)$, the rest of the gemini surfactants are located between the two ion pairs in the upper part of the bilayer and a SLES ion out of the lower part of bilayer. Hence, the curvature of the upper part of the bilayer more decreases than the lower part of bilayer. On the other hand, for Figure 6-(b) $\left(\alpha_{x, s: 1}>0.5\right)$, the curvature of the lower part of the bilayer more decreases than the upper part of bilayer. The mechanism of the vesicle formation for the SLES/CGS I surfactant mixtures is shown in Figure 6.

Particle Size Distribution of Vesicles. Figure 7 shows a particle size distribution of unilamellar vesicle (ULV) at the ratio of SLES/CGSI $=6 / 4$ by $\mathrm{DLS} .{ }^{55}$ The particle size distributions was $40 \mathrm{~nm}-1.1 \mu \mathrm{m}$ and the average size was $180 \mathrm{~nm}$. We obtain quite different results for differently dispersed systems. For SLES CGS1 $=0.01 \mathrm{M}$, it is monodispersed (Figure 7-(a)) after stirred $20 \mathrm{~min}$. But for SLES/CGS ] > $0.015 \mathrm{M}$, a polydispersed system which usually has two distribution peaks (Figure 7-(b) and 7-(c)) is formed in the spectrum. It reveals that to form monodispersed vesicles, a proper mol concen-tration of the surfactant mixtures is necessary.

Images of the Vesicles. Figure 8 gives the images of the vesicles at the mixing ratio of SLES CGSI $=3 / 7$ (Figure 8 (a) : 0.01 M), SLES $/ \mathrm{CGSI}=6 / 4$ (Figure 8-(b) : 0.01 M. Figures 8 -(c) and 8 -(d): $0.02 \mathrm{M})$. Figure 8 clearly shows the existence of an internal cavity surrounded by a unique double layer, the diameter of vesicles is about $180 \mathrm{~nm}$. which is in full agreement with that of DLS.

$\zeta$-Potentials of the Vesicles. Figure 9 presents the $\zeta$ potential of six different samples, namely $0,0.2,0.4,0.6,0.8$ and $I$, as a function of SLES mole fraction. The measured $\zeta$ potentials vary from $-83.1 \mathrm{mV}$, the value from a pure SLES solution at the considered global surfactant concentrations. to $93.0 \mathrm{mV}$, the value for a pure CGSI solution at the same concentration. At $\alpha_{\triangle M}=0,0.2$, and $0.4 \zeta$-potentials were

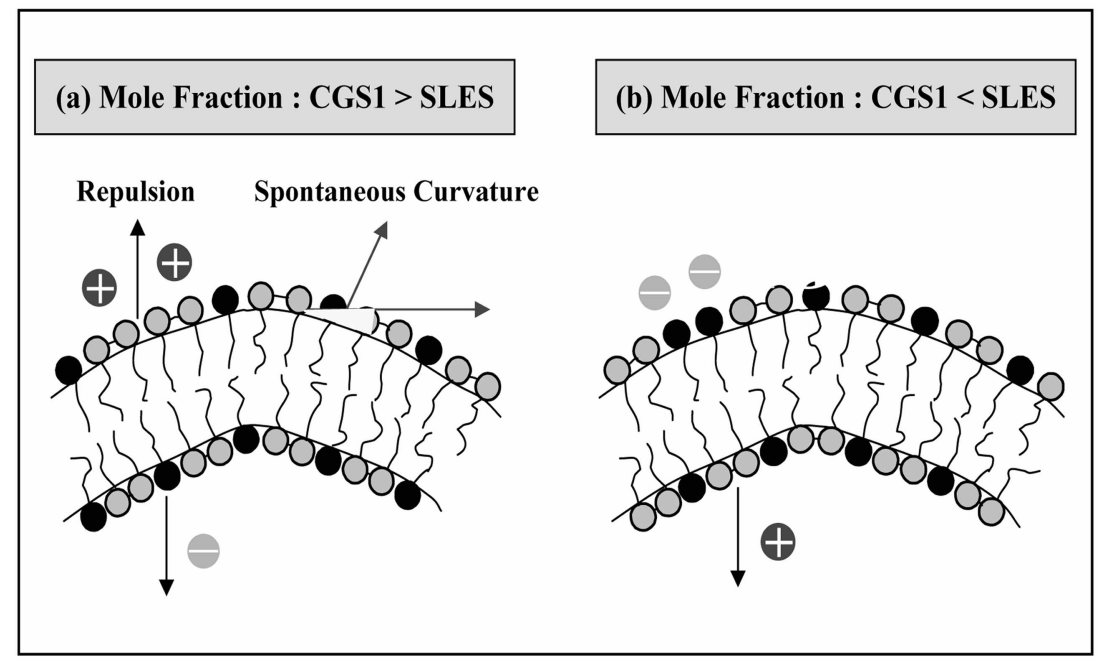

Figure 6. The mechanism of the vesicle formation for the SL.ES/CGSI surfactant mixtures. ((a) : $\alpha_{\mathrm{V} t / .<}<0.5$. (b) $\left.: \alpha_{\mathrm{N}, t .5}>0.5\right)$
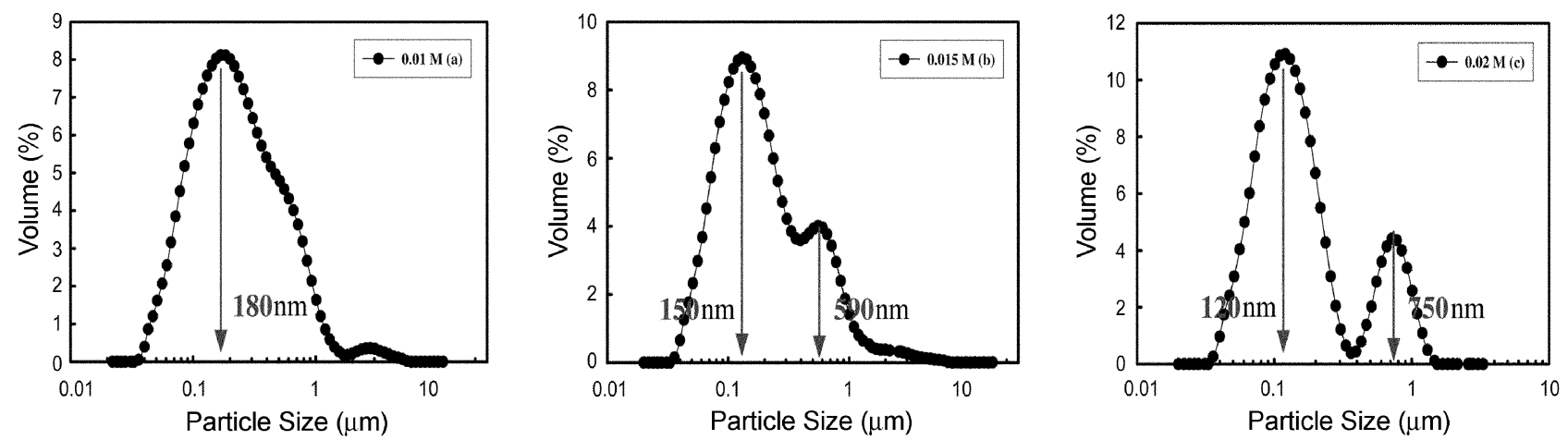

Figure 7. The particle size distribution of a unilamellar vesicle in the aqueous solutions of mixed SL.FS/CGS1 system. (SL.ES/CGSI = 6/4) 

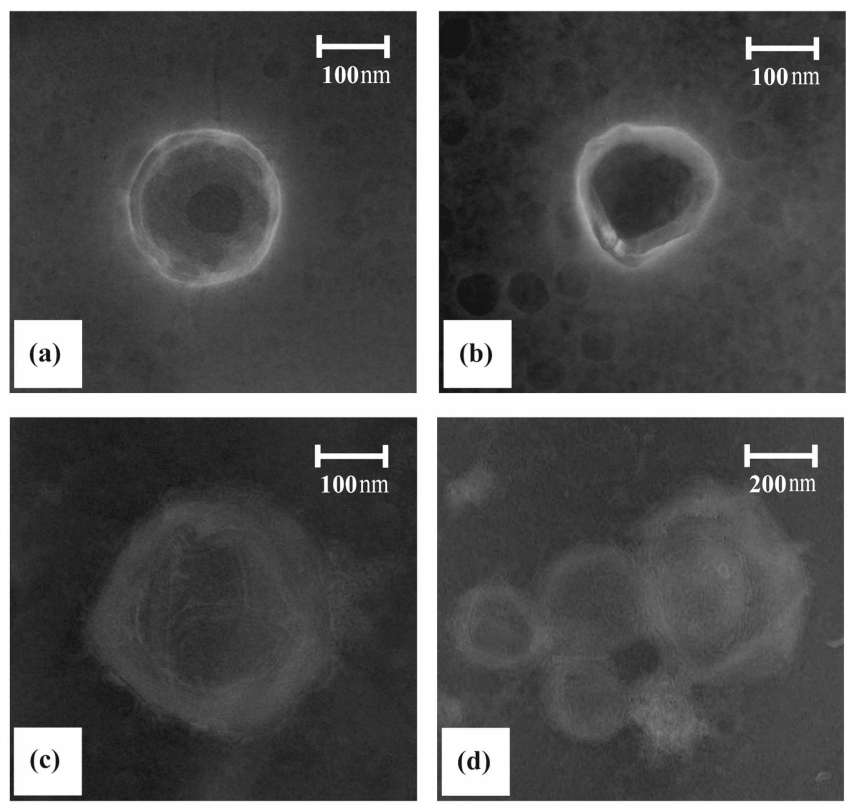

Figure 8. Transmission clectron microscopy (TEM) micrographs of vesicles of SI.F.S/CCRS1 mixed surfactant systems at the mole fraction SI I:S of 0.3 (a) : $0.01 \mathrm{~mol}$ ) and 0.6 . ((b) : $0.01 \mathrm{~mol}$. (c). (d) : $0.02 \mathrm{~mol}$ ).

positive, as expected. Meanwhile. The $\zeta$-potentials were almost identical in a 0.0-0.4 mole fraction of SLES and then decreased suddenly.

At $\alpha_{\mathrm{s}, \mathrm{S}}=0.6 \%$-potential was weakly negative and at $\alpha_{\mathrm{i} / \mathrm{i}}=0.8$ and 1.0 a-potentials were strongly negative. Therefore, at larger concentrations of either surfactant, the vesicles appear to be stable due to large absolute $\zeta$ potentials.

At the SLES/CGSI ratios between $4 / 6$ and $6 / 4$, the point of zero zeta (pzz) potential is achieved for the air-water interface. This implies that the isoelectric point (iep) is located somewhere between these ratios of the surfactants.

Stability of the Vesicles. Figure 10 shows the UV-Vis spectra of the vesicles right after their formation and after

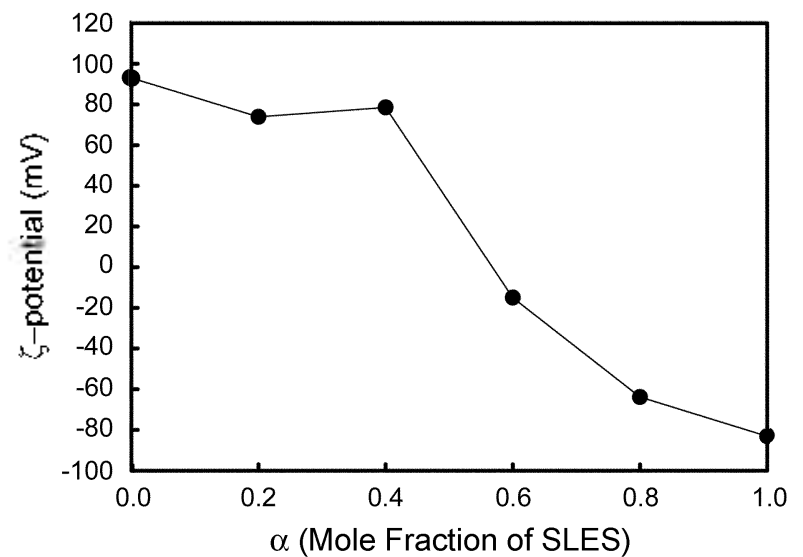

Figure 9. Ihe zeta polentials of $10^{-5} \mathrm{M}$ SLLS/CGSI solution al different mole fraction of SLES.

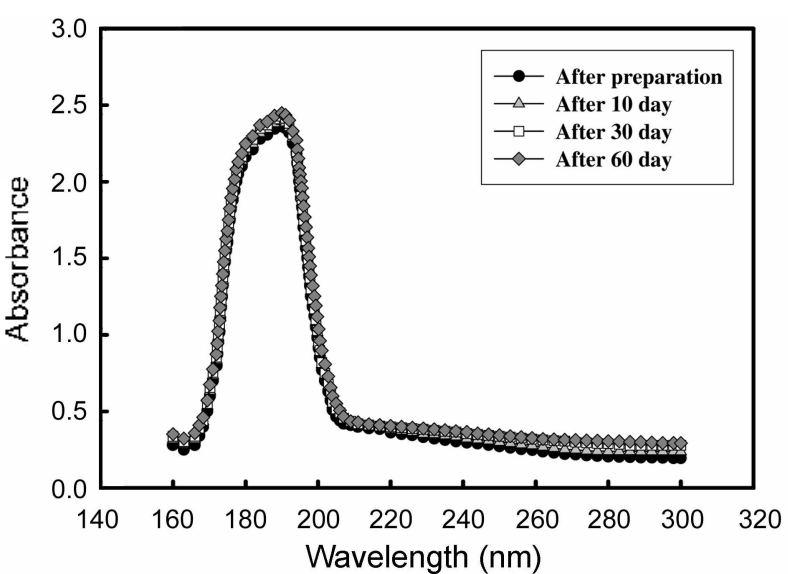

ligure 10. L; V-Vis spectra of $7 \times 10^{-4} \mathrm{M}$ SI.IS/COSl solution at the mole fraction of SLES of 0.4 .

$10,30,60$ days were measured to examine the stability of the vesicles. The absorption maximum of vesicles was situated between 185 and $220 \mathrm{~nm}$. The absorbance remains hardly changed for two months, implying that the vesicles are quite stable during the term. Also, the high absolute values of $\zeta$-potentials in Figure 9 means that the strong repulsive forces among vesicles exist and the stability of vesicles can be manifested.

\section{Conclusions}

In this work the microstructural features of phase behavior formed by cationic CGS1 (Dimeric 1,2-bis (dodecyldimethyl ammonium) ethane dibromide) and anionic SLES (sodium lauryl ether sulfate) surfactants have been investigated. Phase transition temperature increases in a 0.2-0.6 mole fraction of SLES and then decreased suddenly. The mixtures displayed various phase regions. They are the regions of isotropic molecular solution, micellar solution, vesicles, and mixture of micelles and vesicles.

The mixing of cationic and anionic surfactants can form vesicles in pure water, spontaneously, and has the freedom of controlling the interaction between them. The proper geometry combination of the two kinds of molecules leads to the formation of a cuplike structure and ultimately the formation of vesicle. Transmission electron microscopy (lEM) photographs demonstrate the existence of vesicles in the mixture, and presented that the vesicles were of spherical shape and their average size was $180 \mathrm{~nm}$. The spontaneous vesicle formation in mixtures of SLES/CGSI surfactants has been put in relation with the effective spontaneous curvature of the mixed film, which is much more favorable than with a single surfactant.

At larger concentrations of either surfactant. the vesicles appear to be stable due to large absolute zeta potentials. The absorbance remain hardly changed for two months. implying that the vesicles are quite stable for a long time and the absorption maximum of vesicles were situated between 185 and $220 \mathrm{~nm}$. 


\section{References}

1. Gregoriadis. G.: Leathwood. P. D.: Ryman. B. E. FEBS Lett. 1971. $1+95-99$.

2. Knight, C. G. Liposomes in Phnsical Structure to Therapentic Applications: Elsevier: Amsterdam. 1981.

3. Ostro. M. J. Liposomes: Marcel Dekker: New York 1983.

4. Puisieux F.: Delattre. J. Les Liposomes: Applications Therapeutiqnes: Lavoisier Tec et Doc: Paris. 1985.

5. Kiwada, H.: Niinura. H.: Fujisaki. Y.: Yamada, S.: Kato. Y. Chem. Pham. Buhl. 1985, 33,753

6. Arunothayanym. P.: Turton. J. A.: Uehegbul I. F.: Florence, A. T. J. Phorm. Sci. 1999. 88. 34.

7. Papahadjopoulos. D:: Gabizon. A. In Targetting of Drugs 2. Optimizing Strategies: Gregoriadis. G.: Allison. A. C.: Poste. G. Eds.: NATO ASI Ser. 199. Plenum Publishing Corporation: New York 1991: p. 95 .

8. Uchegbu, I. F: Dolble. I. A.: Turton, I. A: Florence. A. T. Phorm. Res. 1995.12 .1019$.

9. Gopi. N.: Devaraj. M. Phamacy thesis. Poona College of Pharmacy University of Pune: 1997

10. Youn, H. C.: Subhash. B.: Fendler. J. H. J. Phys. Chem. 198892. 6320 .

11. Hoffmann. H.: Ulbricht. W. Tenside Surf Det. 1998, 35. 421 .

12. Meagher. R. J.: Hatton. T. A.: Bose. A. Longmuir 1998. H. 4081.

13. Marques. E. F.: Regev. O.: Khan. A.: da Graca Miguel. M.: Lindman. B.J.Phis. Chem. B 1998. 102.6746.

14. Salkar R. A.; Mukesh. D.: Samant. S. D.: Manohar C. Lamgmin 1998, 14, 3778

15. Marques, E. F.: Regev, O.: Khan. A: da Graca Miguel. M.: Lindman. B. J. Phs Chem. B 1999, 103,8353.

16. Kaler. E. W.: Murthy A. K.: Rodriguez. B. E.: Zasadrinski. T. A. N. Sici. 1989. 245.1371.

17. Chiruwolu. S.: Istraelachvili. J. N.: Naranjo. E.: Xu. Z.: Zasadzinski. J. A. Lamgmir 1995, 11.4256.

18. Bergstrom. M.: Pedersen. J. S. Lamgmir 1999, 15, 2250

19. Bergstrom. M.: Pedersen. J. S. J. Plys. Chem. B 1999. 103. 8502.

20. Sakai. H.: Matsumura. A.: Yokoyama. S.: Saji. T.: Alse. M. $J$. Phvs. Chent. B 1990.103. 10737.

21. Samiey. B: Alizadeh. K:: Moghaddasi. M:: Mousavi. M.: Alizadeh. N. Bull. Korem Chem. Soc. 2004, 25.726.

22. Bergstrom. M.: Pedersen. J. S. Lamgmuir 1998, 14, 3754.

23. Marques. E.: Khan. A. da Gracia Miguel. M.: Lindmann, B. $J$. Phvs. Chent 1993, 97, 4729.

24. Kimizuka. N.: Wakiyama. T.: Kunitake. T. J. Am. Chem. Soc. 1996. 118.5808 .

25. Brady, J. E.: Evabs, D. F.: Kacharr. R: Ninham, B. W. J. Am. Chem. Soc. 1984. 106. 4279 .
26. Chunng. Y.C.: Lee. H.-T.: Park. T.Y. Bull. Korean Chem. Soe 1998. 19. 1249.

27. Chung. Y.-C.: Lee. H.-T: Park. T-Y. Bull. Korean Chem. Soc. 1999. 20,16

28. Coi. T.-S.; Shimizu. G.; Shirai. M.; Hamada, K. Dyes Pigments 2000. 45,145

29. Berijelloum. M.: Van der Voort. M.: Cool. P.: Collart. O.: Vansant. E. F. Phos. Chent 2001. 3. 127

30. Camilleri. P. Chent Conmum. 2000.1253.

31. Menger, F. M.; Binder, W. H.; Keiper. J. S. Lamgmair 1997, 13. 3247 .

32. Bhattacharya, S.; De. S. Langmir $1990,15,3400$.

33. Bhattacharya. S.: De. S.: Subramanian. M. J. Org. Chent 1998. 63.7640 .

34. Blanzat. M.: Perez. E.: Rico-Lattes. I.: Prome. D.: Prome. I. C.: Lattes, A. Langmuir 1999, 15.6163.

35. Blanzat, M.; Perez, E; Rico-Lattes. I. New J. Chem 1999, 23. 1063.

36. Zemb. T.: Dubois. M.: Deme. B.: Gulik-Kızywicki. T. Sci. 1999. 283.816.

37. Caillet. C.: Hebrant. M.: Tondre. C. Langmit 2000. 16. 9099.

38. Caillet, C. Thesis. Universite Henri: Poincare-Nancy. 2000; p 1.

39. Hoftmann, H.: Ulbricht. W. Recent Res. Dev. Phus. Chem. 1998. 2. 113 .

40. Bergstrom. M.: Pedersen. J. S.: Schurtenberger. P.: Egelhaaf. S. U. J. Phws. Chem. B 1999. J03. 9888.

41. Marques. E. F. Lamgmir 2000. 16. 4798

42. Safran, S. A.Ad Phys. 1999. 48.395.

43. Villeneuve, M.; Kaneshina. S.: Imae, T:; Aratono, M. Langmiv 1999. 15, 2029 .

44. Kim. H: Lim. K. Bull. Korem Chem. Soc. 2003.24 .1449$.

45. Tabata. Y: Ueno. M.: Meguro. K. J.Ant. Oil Chem. Soc. 1984. 61. 1123.

46. Von Smoluchowski, M. Z. Phus. Chem 1918, th, 1 .

47. Van Gils. G. E.: Kruyt. H. R. Kolloid Chem. Beih. 1936. 46, 60

48. Henry D. C. Proc. R. Soc. London A 1931. 133. 106.

49. Ohshima. H. J. Coll Interf. Sci. 1994. 168. 269.

50. Oh. S.: Moon. S.: Lee. D.: Lee. D.: Kang. Y. Bull Korew Chent Soc. 2004. 25. 280 .

51. Rosen. M. J. Cohen. A. W.: Dahanayake. M; Hua. X. Y. J. Phus. Chem. 1982, 86, 54

52. Israelachvili. J. N. In Inermolectar and Suface Fores: Academic Press: New York. 1991.

53. Israelachiili. J. N.: Mitchell. D. J: Ninham. B. W. J. Chent. Soc. Faraday Trans. 1976. 272. 1525.

54. Yukishige, K.: Hirotaka, U.: Norio, Y.; Katsuliro. N.; Masahiko. A. Langmir $1995.11,2380$.

55. Kim. H.: Lim, K. Bull. Korean Chem. Soc. 2004, 25, 382 